\title{
ECONOMETRIC ANALYSIS OF THE RELATIONSHIP \\ BETWEEN INNOVATION AND FOREIGN TRADE DISTANCE IN CENTRAL \\ AND EASTERN EUROPE COUNTRIES*
}

\author{
Marcin Salamaga, Ph.D., Associate Professor \\ Cracow University of Economics \\ College of Economics, Finance and Law, Department of Statistics \\ Rakowicka 27, 30-510 Kraków, Poland \\ email:salamaga@uek.krakow.pl \\ ORCID: 0000-0003-0225-6651
}

Received 25 October 2019, Accepted 10 March 2020

\begin{abstract}
Research background: Posner's technology gap theories and Vernon's product life cycle assume that differences in innovation and technology levels are the cause of foreign trade. These theories are subject to empirical verification. To date, however, the analysis of the impact of innovation distance on a country's export competitiveness is omitted. This article tries to fill this research gap. The author attempts to examine the relationship between the innovation gap and export competitiveness in industries with varying levels of technological advancement.

Purpose: The aim of the article is to research the direction and strength of the impact of the innovation gap on export competitiveness in 10 different industries in Central and Eastern Europe countries (CEECs).

Research methodology: Dynamic panel models were used in the research, which describe the impact of the technological gap on the export competitiveness of countries. To measure innovation, the indicator of innovative comparative advantage was constructed and based on the number of patents used. The technological gap in individual countries was calculated as the Euclidean distance indicators of the innovative advantage in a given country from other countries.

Results: In light of the presented results of the study, it can be concluded that innovation generally has a significant and positive impact on the competitiveness of exports in the high and medium-high technology industries of the CEECs, while it does not significantly affect the competitiveness of trade in low technology industries. In addition, the Visegrad countries in the high and medium-high technology industries generally have a low technological gap and a smaller distance in export competitiveness using the dynamic panel data model.
\end{abstract}

\footnotetext{
"Publication was financed from funds allocated to Faculty of Management (Cracow University of Economics) within grants to maintain research capacity.
} 
Novelty: The added value of this article is an innovative study on the impact of the technological gap on export competitiveness with the example of the CEECs using the dynamic panel data model.

Keywords: export competitiveness, innovation gap, panel data model, technological gap theory

JEL classification: B17, O3, C23

\section{Introduction}

Innovation and a knowledge-based economy are one of the most important drivers of economic development. The implementation of the newest technical solutions by enterprises, continuous improvement of the existing production and management organization is often one of the prerequisites for their effective competition and staying on the market. The new innovative solutions often give companies many opportunities to increase market share, increase economies of scale and acquire new market niches. The implementation of a completely new or modified product, service, production process, marketing tools or public relations often opens new opportunities for a company on the local and international market. In practice, innovations can therefore have a product character (introduced product is different from existing products in terms of purpose or having completely new features and functions) or process character (improvement of production methods, organization, distribution, and logistics, etc.) (GUS, 2019). In particular, innovation in the sphere of organization and production techniques often referred to as technological innovations determine the level of technological development in the economy. The level of technological advancement of a country influences the shape of the economy by being one of the key elements of the network of multidirectional relationships with many macroeconomic variables. One of them is the relationship between the level of innovation in the economy and foreign trade. Since the export competitiveness of goods is the easiest way to increase market share, from the point of view of the technological gap theory, it seems interesting and reasonable to examine whether the technological distance between countries is reflected in the distance in a country's export competitiveness. While the impact of technological distance on foreign trade has been the subject of research, there is no more extensive research on the impact of technological distance on distance in foreign trade competitiveness has not been carried out so far. This article attempts to fill this research gap. The author set the goal of empirical verification of the relationship between the technological gap and the distance in export competitiveness on the example of the CEECs. For its implementation, a technological 
and trade gap measure and panel dynamic models were constructed. The research hypothesis is as follows: the impact of the innovation gap on the competitiveness of exports depends on the degree of technological advancement of the industry. The study was conducted in relation to branches of industry of various technological advancement, which allowed assessing them in terms of the sensitivity of the impact of innovation on foreign trade. Such knowledge will make it possible to identify the branches in which investments in innovation will increase the competitiveness of foreign trade to the greatest extent.

\section{Literature review}

The issue of the impact of technology and innovation on foreign trade is present in economic theory and empirical research. Some of the economic theories assume that the reason for trade is differences in the technological development of countries. These include the Posner technology gap theory (Posner, 1961), which assumes that differences in technological potential between innovator countries and lagging countries shape their international exchange. The innovator country - net exporter initially has a technological and comparative advantage, but over time the technological gap decreases and foreign producers imitate imported products, which cause the loss of a privileged position in trade by the innovator country. In a sense, the development of Posner's theory is the product life cycle theory (Vernon, 1966), according to which the innovator country (with sufficiently advanced production techniques) exports products to countries that originally did not have the ability to manufacture these products. Over time, these countries become "imitators" and themselves produce and export products. Research in this area is conducted using data from individual countries as well as panel data. L. Soete (1981) and G. Dosi, K. Pavitt and L. Soete (1990) showed a strong relationship between competitiveness in trade and technological advantage for OECD economies. For the economies of the Far East (South Korea, Singapore, Hong Kong) similar relations were presented by P. Uchida and Y. Cook (2004). More complex feedback relationships between trade and technology were shown by S. Lall (1992). The research on the relationship between the technological advancement of a country, foreign trade and other macroeconomic variables was also conducted by L. Soete, B. Verspagen (1994), K. Wakelin (1998), S. Barcenilla, C. Lopez-Pueyo (2000), W. Milberg, E. Houston (2005). At the microeconomic level (enterprise research), the relationships in question were studied by S. Clerides, S. Lach and J. Tybout (1998). To analyze the relationship between the market power of an enterprise and innovation, econometric models are usually used, taking into account variables such as expenditure on research and development, number 
of patents, labor costs, investments, export, and GDP. Empirical research taking into account the technological gap was carried out by G. Dosi, L. Soete (1983) and W. Milberg, E. Houston (2005), I. Granda, A. Fonfría 2009. According to Posner's technology gap theory, differences in the level of technological development of countries' generate trade; therefore a possible distance in the export position of countries at least at the beginning is relatively large. According to Posner's theory, this distance changes over time, because the imitator country will be able to produce the imported product by itself due to the reduction of the output and imitation gap. Due to the different level of development of sectors and industries in economies, the phenomena of the reduction of the technological gap may occur with varying intensity and bring benefits to trade first to innovators and then to imitators. So countries (exporters or importers) can gain or lose shares in individual industry markets. Therefore, studying the effects of reducing the technological gap requires a detailed comparative analysis of the competitive position in individual sectors of the economy. The empirical research conducted so far for OECD countries at the level of economic sectors confirms that the technological gap between countries may result in an imbalance in foreign trade, but the intensity and direction of these interactions depend on the degree of technological advancement of the industry (Granda, Fonfría, 2009). Many studies show that, the value of exports per capita or as the share of exports in GDP or in the total value of exports of reference countries is taken into account to determine a country's trade position (Baracenilla, Montavez, 2000; Milberg, Houston, 2005; Granda, Fonfría, 2009). Since the export competitiveness of goods is the easiest way to increase exports, increase market share, from the point of view of the technological gap theory, it seems interesting and reasonable to examine whether the technological distance between countries is reflected in the distance in a country's export competitiveness. This article will study the competitiveness of foreign trade, which most often determines the international economic position of the entire country.

\section{Research methodology}

The essence of this article is to assess the impact of the technological gap on the distance in export competitiveness of goods. One of the most frequently used measures of export competitiveness is the Revealed Comparative Advantage Index (RCA index) proposed by B. Balassa (1965). It expresses the ratio of the export value of the analyzed commodity group of a given country in the total export value of that country to the share of the export value of the given commodity group in reference countries in the total value of exports in these countries. It can be expressed as follows: 


$$
R C A_{i}=\frac{E x_{i j}}{E x_{j}}: \frac{E x_{i}^{R}}{E x^{R}}
$$

where:

$E x_{i j}$ - the value of exports in the $i$-th sector in the $j$-th country,

$E x_{j}$ - the value of exports in the $j$-th country,

$E x_{i}^{R}-$ the value of exports from the $i$-th sector in reference countries,

$E x^{R}-$ total value of exports in reference countries.

The index (1) values are non-negative and can be arbitrarily high. The lack of normalization of this indicator results in its undesirable properties leading to a complete lack of comparability of its value in time and space (Salamaga, 2013), therefore in this article the indicator has been normalized to the range $[-1 ; 1)$ using the following rational function with the parameter $a=1$ :

$$
S R C A_{c}^{a}=\frac{R C A^{a}-1}{R C A^{a}+1}
$$

The distance in export competitiveness in $T$-periods for the $l$-th country relative to the group of $n$ reference countries in the $i$-th industrial sector was calculated as the Euclidean distance of the indicator (2) for a given country from the rest of the countries:

$$
d_{-} S R C A_{l}^{(i)}=\sqrt{\sum_{k=1}^{n} \sum_{t=1}^{T}\left(S R C A_{l t}^{(i)}-S R C A_{k t}^{(i)}\right)^{2}}
$$

The technological gap is most often defined as a delay in the technological development of one country's economy relative to a selected country or group of reference economies. The technology gap measures in their construction should therefore basically be based on absolute or relative differences between economies in the levels of indicators used to assess the level of innovation development. Therefore, these measures can be created using expenditure on $R \& D$, employment in innovative sectors, the number of patents granted, trademarks, industrial designs, etc. In this study, the number of patents was used to construct the technology gap measure. The indicator of the innovative comparative advantage was constructed in an analogous way as the indicator (1):

$$
I C A_{i}=\frac{P_{i j}}{P_{j}}: \frac{P_{i}^{R}}{P^{R}}
$$

where:

$P_{i j}-$ the number of patents in the $i$-th sector in the $j$-th country, 
$P_{j}$ - the total number of patents in the $j$-th country,

$P_{i}^{R}$ - the number of patents in the $i$-th sector in reference countries,

$P^{R}-$ the total number of patents in reference countries.

The higher the indicator value (3), the higher the relative innovation advantage of the country. For the purposes of this study, the index (3) values have been normalized in the range $[-1 ; 1)$ by applying a transformation using a rational function analogous to that in the index (2). The technological gap occurring over the $T$-years in the $i$-th sector for the $l$-th country was calculated as the Euclidean distance of the corrected index $\operatorname{SICA}_{c}^{a}$ (assumed $a=1$ ) for that country from other countries forming the reference group:

$$
d_{-} S I C A_{l}^{(i)}=\sqrt{\sum_{k=1}^{n} \sum_{t=1}^{T}\left(S I C A_{l t}^{(i)}-S I C A_{k t}^{(i)}\right)^{2}}
$$

In the study of the relationship between the d_SRCA and d_SICA indicators, a dynamic panel data model was used, which was conditioned on the one hand by the panel nature of the data (values of the d_RICA and d_SICA indicators in the CEECs observed in each of 20012018), and on the other - the need to take into account the impact of historical distance values in foreign trade competitiveness on current inequalities in foreign trade competitiveness. The initial form of the model equation is as follows:

$$
d_{-} S R C A_{m t}^{(i)}=\beta_{0}^{(i)}+\varphi^{(i)} d_{-} S R C A_{m t-1}^{(i)}+\beta_{1}^{(i)} d_{-} S I C A_{m t}^{(i)}+\varepsilon_{m t}
$$

where:

$d_{-} S R C A_{m t}^{(i)} \quad$ - the vector of the value of the d_SRCA indicator in the $i$-th product group for the $m$-th level in the period $t$,

$d_{-} S R C A_{m t-1}^{(i)} \quad$ - the vector of the d_SRCA indicator value in the $i$-th product group for the $\mathrm{m}$-th level in the $t-1$ period,

$d_{-} S I C A_{m t}^{(i)} \quad-$ the vector of d_SICA indicator value in the $i$-th product group for the $m$-th level in the period $t$,

$\beta_{0}^{(i)}, \varphi^{(i)}, \beta_{1}^{(i)}-$ the model parameters,

$\varepsilon_{m t}-$ the vector of the value of the error term for the $m$-th level in the period $t$.

The estimation of the equation (6) was carried out using the two-step Generalized Method of Moments (GMM), the effectiveness of which is confirmed in numerous studies using dynamic panel models. This method of estimation limits the problem of variable endogenicity and the 
correlation of variables with the error term that can occur in dynamic panel data models. Data for calculations come from the Comext database (Eurostat), and data on patents - from the database of the World Intellectual Property Organization (WIPO). The study includes 7 countries of Central and Eastern Europe: ${ }^{1}$ the Czech Republic, Estonia, Hungary, Latvia, Lithuania, Poland, the Slovak Republic, and the time range of the analysis covers the years 2001-2018.

\section{Results of the empirical research}

According to neotechnological theories of economics, differences in endowments with production factors intensify foreign trade flows. It seems that they should also affect the very competitiveness of foreign trade. Is this really the case and what is the relationship like in Central and Eastern Europe? This will be the subject of the study in this section. In the first stage of the study, the nature of the relationship between the technological gap and the distance in trade competitiveness for countries of Central and Eastern Europe in bilateral terms was examined. The analysis was carried out for various industries. This study will present the results of this analysis for the transport, fuel and energy, and agri-food industries. They represent high, medium and low technology industries, respectively. Figure 1 shows curves representing the technological gap and distance in trade competitiveness of agri-food industry goods for pairs of the CEECs.

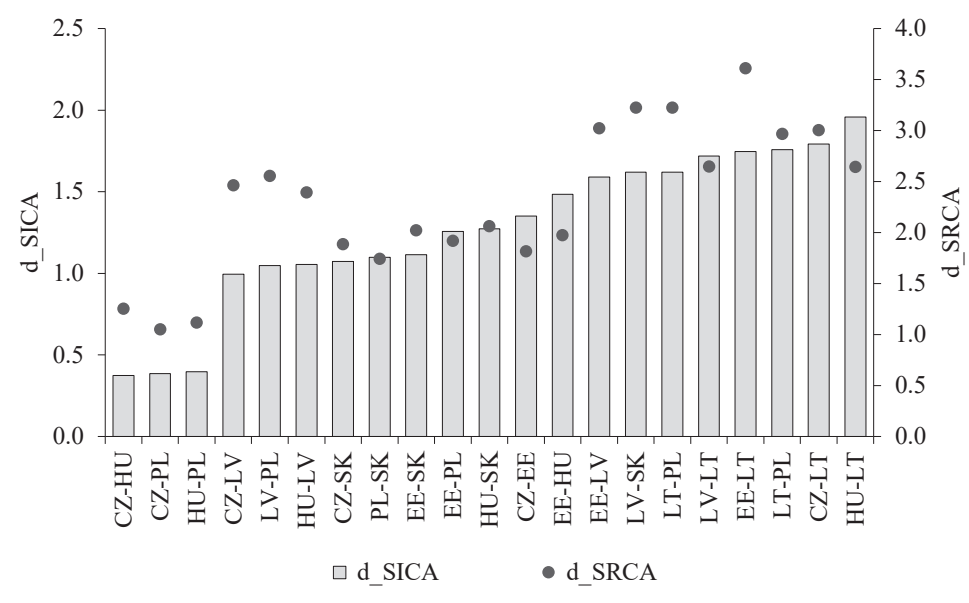

Figure 1. Relations between the innovation gap and the distance in foreign trade competitiveness in the fuel and energy industry in the CEECs in bilateral terms in 2001-2018

Source: own elaboration based on Comext and WIPO.

\footnotetext{
1 The study included countries that joined the EU in 2004, have similar economic potential and geographical proximity, historical conditions.
} 
Figure 1 shows that the widening of the innovation gap is accompanied, on average, by the increase in disparities in the foreign trade competitiveness of fuel and energy products. The lowest innovation gap and the smallest distance in trade competitiveness were recorded in the following pairs of Visegrad Group countries: the Czech Republic and Hungary, the Czech Republic and Poland as well as Hungary and Poland. In turn, a relatively large technological gap with a relatively high distance in trade competitiveness is recorded by Lithuania in comparison with Poland, Hungary or the Czech Republic.

Figure 2 presents curves of the technological gap and distance in trade competitiveness with goods of the vehicle manufacturing industry in the countries of the CEECs.

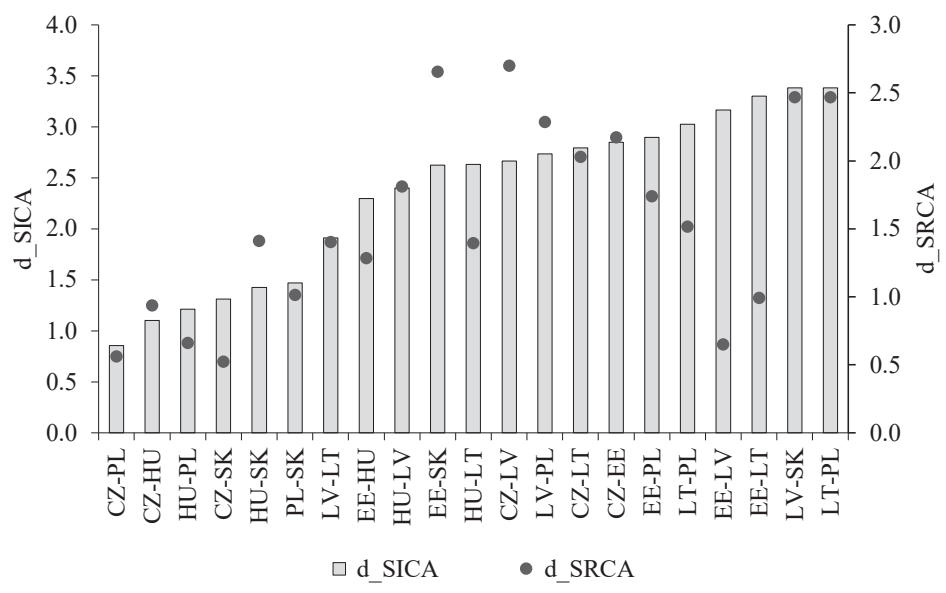

Figure 2. Relations between the innovation gap and the distance in foreign trade competitiveness in the vehicle manufacturing industry in the CEECs in bilateral terms in the years 2001-2018

Source: own elaboration based on Comext and WIPO.

In the vehicle manufacturing industry, the relationship between the innovation gap and the distance in foreign trade competitiveness are no longer as clear-cut as in the case of the fuel and energy industry. For some countries (especially the Visegrad Group countries) the lower technology gap is accompanied by smaller inequalities in trade competitiveness. But many pairs of countries can also be identified in which the high technological gap is accompanied by a relatively low distance in trade competitiveness (e.g. Estonia and Latvia or Estonia and Lithuania). Thus, the ability to generate foreign trade in the vehicle manufacturing industry as a result of a technological gap depends on the particular country. 
Figure 3 Presents curves of the technological gap and distance in foreign trade competitiveness with the agri-food industry goods in the CCECs.

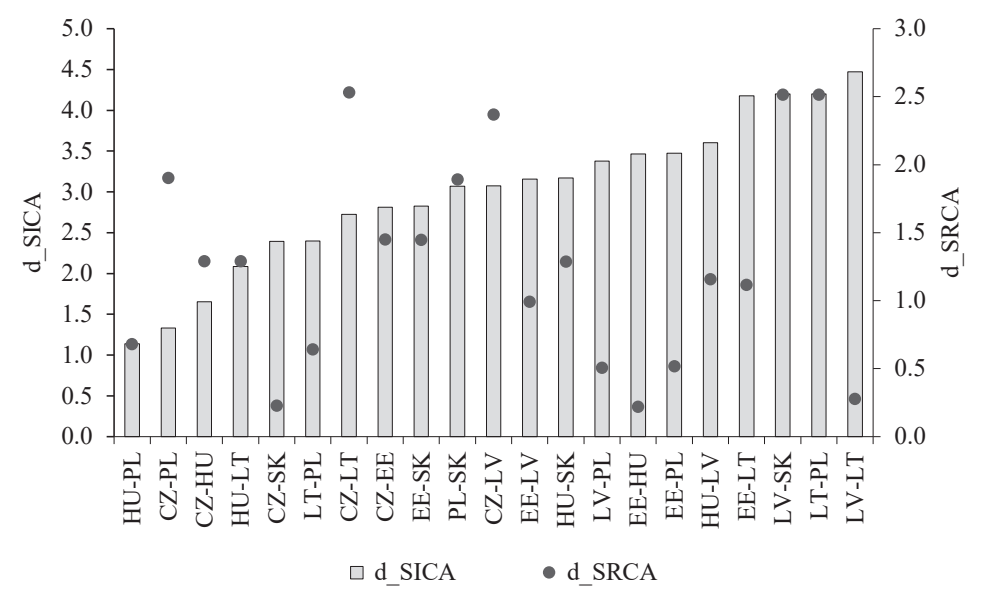

Figure 3. Relations between the innovation gap and the distance in foreign trade competitiveness in the agri-food industry in the CEECs in bilateral terms in 2001-2018

Source: own elaboration based on Comext and WIPO.

In the agri-food industry it is difficult to indicate the clear relationship between the innovation gap and the distance in foreign trade competitiveness. The growing technological gap is accompanied by changes in technological distance similar to random walk. It can be assumed that in most of the countries surveyed the technological gap does not affect the competitiveness of foreign trade in agri-food products.

Table 1 shows the results of the correlation coefficients calculated for the ten industries between the technological gap and the distance in foreign trade in the CEECs.

Based on Table 1 it can be concluded that a positive and statistically significant correlation between the technological gap and the distance in foreign trade competitiveness was found in the following industries: vehicle manufacturing, electrical, electronic and precision, chemical, metallurgical and metal. In other industries, no statistically significant correlation was found between the figures in question. Statistically significant relationships relate mainly to industries belonging to high and medium high-tech and medium high-tech industries. The reason for this may be the particular sensitivity of these industries to the progress of innovation and strong dependence on the latest technological solutions. It is indisputable that technological advantage and innovation are reflected in the competitiveness of exports of technologically advanced 
goods. In industries that are less technologically advanced, export competitiveness may be more determined by factor costs or raw material resources than innovation.

Table 1. Results of correlation coefficients between the technological gap and distance in foreign trade in the CEECs

\begin{tabular}{|l|c|c|}
\hline \multicolumn{1}{|c|}{ Industry } & Correlation coefficient & p-value \\
\hline Agri-food & 0.0572 & 0.804 \\
\hline Fuel, energy and mineral & 0.0649 & 0.378 \\
\hline Chemical & 0.2484 & 0.001 \\
\hline Light & -0.0463 & 0.529 \\
\hline Wood and paper & 0.0131 & 0.859 \\
\hline Metallurgical and metal & 0.1651 & 0.024 \\
\hline Machine & -0.0247 & 0.738 \\
\hline Electric, electronic and precise & 0.1586 & 0.030 \\
\hline Vehicle manufacturing & 0.3314 & 0.000 \\
\hline Others & 0.1375 & 0.061 \\
\hline
\end{tabular}

Source: own calculations based on Comext and WIPO.

To estimate the cause and effect relationship between the distance in foreign trade competitiveness and the technological gap, a dynamic panel data model was used (1). The model was estimated separately for a group of industrial branches of various technological advancement. This allowed assessing whether the direction of the technological gap impact on the country's foreign trade competitiveness depends on the degree of technological advancement of the economic sector. The final model was based on Sargan and Wald test results. Table 2 presents the assessment of model parameters for highly technologically advanced industries, which include industries: chemical, pharmaceutical, transport, electronic and precision industries.

Table 2. Results of the estimation of the dynamic panel data model in high-tech industries

\begin{tabular}{|l|c|c|c|c|}
\hline \multicolumn{1}{|c|}{ Explanatory variable } & Estimate of parameter & Stand. error & z & p-value \\
\hline const & 1.322 & 1.073 & 1.232 & 0.218 \\
\hline d_SICA & 0.393 & 0.026 & 14.838 & 0.000 \\
\hline d_SRCA(-1) & 0.531 & 0.072 & 7.417 & 0.000 \\
\hline d_SRCA(-2) & -0.220 & 0.047 & -4.655 & 0.000 \\
\hline
\end{tabular}

Source: own calculations based on Comext and WIPO. 
The results indicate that in technologically advanced branches the technological gap has a positive and statistically significant impact on the distance in foreign trade. Historical values of the distance of the disclosed comparative advantage in the previous year (two years back) positively (negatively) and significantly affect the current gap in foreign trade. Table 3 presents the estimation results of the model for medium technological advancement industries (fuel and energy, metal, machinery, electromechanical, and other products).

Table 3. Results of the estimation of the dynamic panel data model in medium high-tech industries

\begin{tabular}{|l|c|c|c|c|}
\hline \multicolumn{1}{|c|}{ Explanatory variable } & Estimate of parameter & Stand. error & z & p-value \\
\hline const & -0.796 & 0.167 & -4.772 & 0.000 \\
\hline d_SICA & 0.056 & 0.007 & 8.008 & 0.000 \\
\hline d_SRCA(-1) & 0.498 & 0.107 & 4.679 & 0.000 \\
\hline d_SRCA(-2) & -0.218 & 0.304 & -0.717 & 0.473 \\
\hline
\end{tabular}

Source: own calculations based on Comext and WIPO.

Based on the results of (Table 3), it can be concluded that in medium-high-tech industries the technology gap has a positive and statistically significant impact on the distance in foreign trade, but this impact is weaker than in the case of the high-tech industry. The historical values of the trade competitiveness distance in the previous year also significantly affect the current gap in foreign trade, while the values of the distance in trade competitiveness lagged by 2 years do not have a significant impact on current competitiveness in foreign trade. Table 4 presents the estimation results of model parameters for low-tech industries (mineral, agri-food, wood and paper, light).

Table 4. Results of the estimation of the dynamic panel data model in low-tech industries

\begin{tabular}{|l|c|c|c|c|}
\hline Explanatory variable & Estimate of parameter & Stand. error & $\mathrm{z}$ & p-value \\
\hline const & 1.317 & 0.236 & 5.575 & 0.000 \\
\hline d_SICA & 0.093 & 0.098 & 0.951 & 0.342 \\
\hline d_SRCA(-1) & 0.190 & 0.080 & 2.375 & 0.018 \\
\hline
\end{tabular}

Source: own elaboration based on Comext and WIPO.

Based on the results of Table 3, it can be concluded that in low technology branches the technological gap has no statistically significant impact on the distance in foreign trade. Only 
the historical values of the trade competitiveness distance in the previous year positively and significantly affect the current gap in foreign trade.

\section{Conclusions}

In the light of the presented results of the study, it can be concluded that innovation generally has a significant and positive impact on the competitiveness of exports in high- and medium-high-tech sectors of CEECs, while it does not significantly affect the competitiveness of trade in low-tech branches. In addition, the technology gap has the strongest impact on the foreign trade distance in high-tech industries. At the level of individual industrial branches of the countries studied, the nature of the relationship between technological and foreign trade distance varies depending on the ability of countries to inter-sectoral technological rivalry. The obtained results are similar to those of other authors (Granda, Fonfría, 2009; Wakelin, 1998), but it should be emphasized that other authors study the impact of technological distance on inequalities in foreign trade (and not on export competitiveness). These results confirm the strong and positive impact of technological distance on inequalities in foreign trade mainly in the high tech industry. The results presented in the work allow indicating those industrial branches in which the increase of innovativeness will contribute to increasing the competitiveness of foreign trade. Such knowledge can be valuable for both investors and decision-makers responsible for measures supporting innovation. Summing up the obtained results, it should be noted that the issues taken up in the article require further research, including other variables used to assess innovation (e.g. R\&D expenditure, the number of scientific articles per 1 million inhabitants, and employment in high-tech industries).

\section{References}

Balassa, B. (1965). Trade Liberalisation and 'Revealed' Comparative Advantage. Manchester School of Economics and Social Studies, 33, 99-123.

Barcenilla, S., Lopez-Pueyo, C. (2000). Macroeconomic competitiveness in the Europe of twelve: An application to 1969-93. IAER, 6 (4).

Cieślik, A. (2000). The new theory of foreign trade in the light of empirical research. Warszawa: Wydawnictwo Naukowe PWN. 
Clerides, S., Lach. S., Tybout, J. (1998). Is learning by exporting important? Micro-dynamic evidence from Colombia, Mexico, and Morocco. The Quarterly Journal of Economics, August, 903-947.

Cook, P., Uchida, Y. (2004). The Effects of Competition on Technological and Trade Competitiveness: A Preliminary Examination, Centre on Regulation and Competition. Working Paper Series, 72.

Dosi, G. Pavitt, K., Soete, L. (1990). The economics of technical change and international trade. London: Harvester Wheatsheaf.

Granda, I., Fonfría, A. (2009). Technology and economic inequality effects on international trade. $W P, 02 / 09$.

GUS (2019). Science and technology in 2017. Statistical analyzes. Warszawa-Szczecin: Central Statistical Office in Szczecin.

Lall, S. (1992). Technological capabilities and industrialisation. World Development, 20, 165186.

Milberg, W., Houston, E. (2005). The high road and the low road to international competitiveness: extending the neo-shumpeterian trade model beyond technology. International Review of Applied Economics, 19 (2), 139-161.

Porter, M.E. (1985). Competitive Advantage. Creating and Sustaining Superior Performance. New York: The Free Press.

Porter, M.E. (1990). The Competitive Advantage of Nations. New York: The Free Press.

Posner, M.V. (1961). International trade and technical change. Oxford Economic Papers, 12, 323-341.

Salamaga, M. (2013). Propozycja modyfikacji wskaźnika ujawnionej przewagi komparatywnej z wykorzystaniem funkcji wymiernych. Zeszyty Naukowe Uniwersytetu Ekonomicznego w Krakowie, 923, 23-35.

Soete, L. (1981). A general test of technology gap trade theory. Weltwirtschaftliches Archiv., $117,638-660$.

Soete, L., Verspagen, B. (1994). Competing for growth: The dynamics of technology gaps. In: L. Pasinetti, R.M. Solow (eds.), Economic growth and the structure of long term development (pp. 272-306). London: St. Martin Press.

Wakelin, K. (1998). The role of innovation in bilateral OECD trade performance. Applied Economics, 30, 1335-1346.

Vernon, V. (1966). International investment and international trade in the product cycle. Quarterly Journal of Economics, LXXX, 190-207. 